\title{
Soil Microbial Community Development in a Cherry Replant Site
}

\author{
Peng Si ${ }^{1,2 \#}$, Wei Shao ${ }^{2 \#, ~ H u i l i ~} \mathrm{Yu}^{2}$, Xiaoxin Shi ${ }^{1}$, Ying Zhang ${ }^{1}$, Guoqiang $\mathrm{Du}^{1 *}$ \\ ${ }^{1}$ College of Horticulture, Agricultural University of Hebei, Baoding, Hebei, 071001, China \\ ${ }^{2}$ Institute of Zhengzhou Fruit Research, Chinese Academy of Agricultural Sciences Zhengzhou, Henan, 450000, China \\ ${ }^{\#}$ Authors are equally contributed
}

Received: 29 December, 2016; Accepted: 03, February 2017; Published: 10, February 2017

*Corresponding author: Guoqiang Du, College of Horticulture, Agricultural University of Hebei, Tel no.: 0086-371-55900985, Fax: 86-37165330987; Email address: sipeng@caas.cn

\begin{abstract}
Introduction: Replant disease has been studied extensively, but it has not been accurately defined and the causal mechanisms have not been elucidated. Understanding the microbial community changes in cherry (Prunus spp. L.) replant soil is important, as soil microbial communities could be affected by planting cherry seedlings and, in turn, they could impact growth of the seedlings.
\end{abstract}

Methods: Biolog Eco Plates and Denaturing Gradient Gel Electrophoresis (DGGE) were used to analyse the genomic and metabolic soil microbial communities of cherry replants.

Results: Community Level Physiological Profile (CLPP) results showed that soil microbial diversity and metabolic activity were enhanced by replanting cherry, and Average Well Colour Development $(A W C D)$, substrate evenness $(E)$, and the utilisation of phenols were positively correlated with cherry continuous replanting number $(\mathrm{r}=$ $0.7107,0.6055$ and 0.6443 , respectively; all $P<0.05$ ). Additionally, DGGE results revealed that there was no obvious difference in soil bacterial community composition, but significant differences in fungal communities, related to the continuous number of cherry plantings, were observed. Analysis of the band sequence indicated that Fusarium oxysporum, Fusarium falciforme, Fusarium solani and Verticillium nigrescens stimulated in RP.

Conclusion: Our results, evidence that uutilisation of phenol and the pathogens in soil play key role in cherry replant systems.

Keywords: Cherry replant site; Soil microbial community; CLPP; DGGE; Soil borne pathogenic fungi

\section{Introduction}

Replant problems, which included poor growth of trees and occurred after replanting the same or closely related species, was caused by biotic and abiotic factors and resulted in severe stunting, shortened internodes, rosetted leaves, small root systems, decayed or discoloured roots, and even death [1-3]. Several lines of evidence indicate that plant-associated microbial communities (biotic factors) are crucial for fruit tree health $[3,4]$. Further research revealed that fungal communities in the rhizosphere as a factor can affect many species of plants growth and yield at replant sites [5-9]. Especially, the soil borne pathogenic fungi in replanted soil such like Fusarium oxysporum, causing vascular wilt and root diseases on a broad range of agricultural plants worldwide, and leading to considerable yield and economic losses [10-12]. However, there is few published paper on whether the soil borne pathogenic fungi was the most critical factors leading to cherry replant disease at present. In addition, replant disease is often related to the plant species, and in terms of fruit trees, even pome and stone fruits have distinct replant problems [13]. Therefore, it is very necessary to study microbial community in cherry replant site.

In assessing functional diversity of the microbial communities in replanting cherry soil, Biolog Eco Plates has been used to acquire microbial CLPPs [14]. Genomic and metabolic analysis of the soil microbial communities would provide an exhaustive approach to characterise microbial communities and identify the factors causing cherry replant disease [15]. Therefore, the objectives of this study were to determine the soil microbial community changes in cherry replanted soil, to explore the relationship between cherry replant disease and certain microbial species, and to clarify the pathogenesis of cherry replantation disease.

\section{Material and Methods}

\section{Site description}

The experiment was performed in a cherry cultivating garden $\left(34^{\circ} 45^{\prime} 5^{\prime \prime} \mathrm{N}, 114^{\circ} 1^{\prime} 34^{\prime \prime} \mathrm{E}\right)$ in Henan province, China. The average elevation of the study area was $78 \mathrm{~m}$ above sea level. The climate was a typical temperate continental monsoon climate, with a mean annual temperature of $14.2^{\circ} \mathrm{C}$. Mean annual precipitation was approximately $616 \mathrm{~mm}$. The top soil contained $58.1 \mathrm{mg} / \mathrm{kg}$ available phosphorus, $145.9 \mathrm{mg} / \mathrm{kg}$ available potassium, 4.78 $\mathrm{mg} / \mathrm{kg}$ ammonia nitrogen, and $76.99 \mathrm{mg} / \mathrm{kg}$ nitrate nitrogen, with a $\mathrm{pH}-\mathrm{H}_{2} \mathrm{O}$ of 6.8 .

\section{Experiment design}

The experiment was performed as described in Table 1. All cherry rootstocks were ' $\mathrm{ZY}-1$ '. The cherry seedlings were first planted in Replanted Plot (RP) January, 2010 and removed in February, 2013. Then cherry seedlings were planted in RP and 


\begin{tabular}{|c|c|c|c|}
\hline \multirow{2}{*}{ Sample code } & \multicolumn{2}{|r|}{ Layer } & \multirow{2}{*}{ Treatments } \\
\hline & $0-20 \mathrm{~cm}$ & $21-40 \mathrm{~cm}$ & \\
\hline NP & NP1 & NP2 & $\begin{array}{l}\text { Never-cherry-planted plot as } \\
\text { control }\end{array}$ \\
\hline FP & FP1 & FP2 & First planted cherry plot \\
\hline $\mathrm{RP}$ & RP1 & RP2 & Replanted cherry plot \\
\hline
\end{tabular}

first planted plots (FP) in July, 2013. Cherry seedlings in RP were affected by replant disease, and inhibition rate of new shoots was higher than $30 \%$. We used a randomized complete block design with three replication. There were five random sampling sites in each plot. Soil samples were collected from each sampling site, and five samples from each site were grouped, and mixed together. A total of $375 \mathrm{~kg} /$ ha compound fertilizer $\left(\mathrm{N}, \mathrm{P}_{2} \mathrm{O}_{5}, \mathrm{~K}_{2} \mathrm{O}\right.$, all at percentages of $15 \%$ ), and $9,000 \mathrm{~kg} /$ ha organic fertilizer, were applied every September in all plots. In addition, no chemicals were used in all plots.

\section{Analysis of the Community Level Physiological Profile (CLPP)}

The community level physiological profile was performed using Biolog Eco Plate ${ }^{\mathrm{TM}}$ (Biolog Inc., CA, USA). Each Biolog Eco Plate contained 31 carbon sources in triplicate and three negative controls in a 96-well-plate format [16]. Briefly, $1 \mathrm{~g}$ of soil was placed in an autoclaved triangular flask with $99 \mathrm{ml}$ of 0.85 $\%$ sterilised $\mathrm{NaCl}$ solution. The soil suspensions were shaken on a reciprocal shaker for $30 \mathrm{~min}$ at a speed of $200 \mathrm{r} / \mathrm{min}$, and then stored at $4^{\circ} \mathrm{C}$ for $30 \mathrm{~min}$. A total of $150 \mu \mathrm{L}$ of solution was placed in each well, and all plates were cultivated at $25^{\circ} \mathrm{C}$ for 192 $\mathrm{h}$. The optical density at both $590 \mathrm{~nm}$ (colour development plus turbidity) and $750 \mathrm{~nm}$ (turbidity only) was read every $24 \mathrm{~h}$ by the Ultra Micro-plated Reader (Elx 808, BIO TEK Instruments Inc., Winooski, VT, USA).

Substrate-related diversity indices were based on Carbon Source Utilisation Patterns (CSUPs). Biolog Eco-plates could also be used to calculate diversity indices. To compare functional diversity within the never-cherry-planted plot (NP), FP, and RP, the $96 \mathrm{~h}$ data, which were in the exponential phase, were used for statistical analysis of the CLPPs [17]. According to Zak et al. [18], the Shannon diversity $(H)$, substrate richness $(S)$, substrate evenness $(E)$, and Simpson dominance $(D)$ on the different carbon substrate guilds were calculated.

\section{Extraction of DNA from soil}

DNA was extracted in triplicate from each sample using the FastDNA® SPIN Kit for Soil (BI0101, Carlsbad, CA, USA).

Bacterial community analysis: PCR was performed with $5 \mu \mathrm{L} 10 \times$ PCR buffer (Applied Bio systems), $3.2 \mu \mathrm{L}$ dNTP mixture2.5 mM, 0.4 $\mu$ l ExTaq $(5 \mathrm{U} / \mu \mathrm{L}$ ), and $1 \mu \mathrm{L}$ GC-338F (CGCCCGGGGCGCGCCCCGGGGCGGGGCGGGGG CGCGGGGGGCCTACGGGAGGCAGCAG) as a forward primer, with GC-clamp and $1 \mu \mathrm{L} 518 \mathrm{R}$ (ATTACC GCGGCTGCTGG) as reverse primers $(20 \mu \mathrm{M}$ each), and $50 \mathrm{ng}$ purified DNA extracts diluted to $50 \mu \mathrm{L}$ with $\mathrm{ddH}_{2} \mathrm{O}$. Amplification was performed at $94^{\circ} \mathrm{C}$ for $5 \mathrm{~min}$, followed by 30 cycles of $94^{\circ} \mathrm{C}$ for $1 \mathrm{~min}, 55^{\circ} \mathrm{C}$ for $45 \mathrm{~s}, 72^{\circ} \mathrm{C}$ for $1 \mathrm{~min}$, and finally $72^{\circ} \mathrm{C}$ for $10 \mathrm{~min}$ [19]. A $10 \mu \mathrm{L}$ aliquot of the PCR products was loaded into $7 \%(\mathrm{w} / \mathrm{v})$ acryl amide gel containing a linear chemical gradient ranging from $35-55 \%$ denaturant. The gels were run for $5 \mathrm{~h}$ at $150 \mathrm{~V}$. After electrophoresis, the gels were soaked in Gel Red solution (GelRedTM Nucleic Acid Gel Stain; Biotium, Hayward, CA, USA) for 30 min and photographed with a Gel-Doc2000 (BioRad Laboratories, Hercules, CA, USA). The different DGGE bands were excised and re-amplified for sequencing with a 338f/518r primer pair.

Fungi community analysis: The forward primers ITS1f 5'-CTTGGTCATTTAGAGGAAGTAA-3' and ITS1f-gc 5'-CGC CCG CCGCGCGCGGCGGG CGGGGCGGGGGCACGGGGGGCTTGGTCATTTAGAGGAAGTAA-3', and the reverse primers ITS2 5'-GCTGCGTTCTTCATCGATGC-3' and ITS4 5'-TCCTCCGCTTATTGATATGC-3', were used in this study. PCR was used to amplify the ITS1 region of the fungal rDNA. A fragment comprising both ITS1 and ITS2 was amplified in the first PCR reaction, using the primer pair ITS1f/ITS4. After purification of the PCR product, the ITS1 region was amplified in the second PCR reaction using the ITS1f-gc/ITS2 primers. The first PCR reaction consisted of $2.5 \mu \mathrm{L} 10 \times$ Ex Tap buffer, $2 \mu \mathrm{L}$ dNTPs $(2.5 \mu \mathrm{M}), 0.25 \mu \mathrm{L}$ ExTaq Polymerase $(5 \mathrm{U} / \mu \mathrm{L})$, $0.5 \mu \mathrm{L}$ ITS1f primer ( $20 \mathrm{pmol} / \mu \mathrm{L}), 0.5 \mu \mathrm{L}$ ITS4 primer $(20 \mathrm{pmol} /$ $\mu \mathrm{L}), 1.5 \mathrm{U}$ DNA polymerase, $1 \mu \mathrm{L}$ DNA template $(50 \mathrm{ng} / \mu \mathrm{L})$, and $0.5 \mathrm{H}_{2} \mathrm{O}$ to bring the volume to $25 \mu \mathrm{L}$. Cycling conditions were $94^{\circ} \mathrm{C}$ for $5 \mathrm{~min}, 35$ cycles at $94^{\circ} \mathrm{C}$ for $1 \mathrm{~min}, 50^{\circ} \mathrm{C}$ for $1 \mathrm{~min}$, and $72^{\circ} \mathrm{C}$ for $1 \mathrm{~min}$, and, finally, $72^{\circ} \mathrm{C}$ for $10 \mathrm{~min}$.

The second PCR reaction consisted of $10 \times$ PCR buffer, 3.2 $\mu \mathrm{L}$ dNTPs (2.5 mM), $0.4 \mu \mathrm{L}$ ExTaq Polymerase $(5 \mathrm{U} / \mu \mathrm{L}), 0.5 \mu \mathrm{L}$ ITS1f-gc primer $(20 \mathrm{pmol} / \mu \mathrm{L}), 0.5 \mu \mathrm{L}$ ITS2 primer $(20 \mathrm{pmol} / \mu \mathrm{L})$, $1 \mu \mathrm{L}$ DNA polymerase, and $1 \mu \mathrm{L}$ of PCR product obtained from the first PCR as a template to bring the volume to $50 \mu \mathrm{L}$ with $\mathrm{ddH}_{2} \mathrm{O}$. Cycling conditions were $94^{\circ} \mathrm{C}$ for $5 \mathrm{~min}, 35$ cycles at $94^{\circ} \mathrm{C}$ for $30 \mathrm{~s}$, $55^{\circ} \mathrm{C}$ for $30 \mathrm{~s}, 72^{\circ} \mathrm{C}$ for $30 \mathrm{~s}$, and, finally, $72^{\circ} \mathrm{C}$ for $10 \mathrm{~min}$.

A $10 \mu \mathrm{L}$ aliquot of the PCR products was loaded into a $7 \%$ $(\mathrm{w} / \mathrm{v})$ acryl amide gel containing a linear chemical gradient ranging from $30-65 \%$ denaturant. The gels were run for $8 \mathrm{~h}$ at 120 V. After electrophoresis, the gels were soaked in Gel Red solution (GelRedTM Nucleic Acid Gel Stain, Biotium) for 30 min and photographed with a Gel-Doc2000 (Bio-Rad Laboratories). The different DGGE bands were excised and re-amplified for sequencing with a ITS1f/ITS2 primer pair.

Statistical analysis: Digitised DGGE images were analysed with Quantity One software. The dice similarity matrix was constructed for all lanes, and Redundancy Analysis (RDA) was performed using Canoco software (ver. 4.5; Microcomputer Power, Ithaca, NY, USA). Data were subjected to one-way analysis of variance (ANOVA) (Dunnett's; $P \leq 0.05$ ).The values in the figures and tables correspond to the average of triplicate replication \pm standard error (SE).

Sequencing and phylogenetic analysis: The 16S rRNA gene sequences of the bacterial and ITS gene sequences of fungi isolates were aligned and a phylogenetic tree was obtained using MEGA 4. The maximum similarity of sequences was checked on 
the web at the National Center for Biotechnology Information (NCBI) by comparing sequences with the nucleotide collection database, using the nucleotide BLAST program.

\section{Results}

\section{Community level physiological profiles (CLPP)}

Community level physiological profiles of the six soil samples were analysed using BiologEcoplate ${ }^{\mathrm{TM}}$. Assays were performed over a $96 \mathrm{~h}$ incubation period (Figure 1; Tables 2, 3). Substrate richness $(S)$ of RP was obviously greater than NP and FP (Table 2 ) in both soil layers (0-20 and 20-40 cm). Additionally, $S$ was found to be slightly lower at the first cherry planting compared to the replanted cherry. Evenness $(E)$ was found to be nonsignificantly different among NP, FP, and RP, while FP and RP were a little greater than NP, revealing that $E$ of substrates could be affected by cherry planting. From the $0-20 \mathrm{~cm}$ soil layer, Simpson dominance $(D)$ of FP1 was significantly higher than NP1 and RP1, indicating that $D$ was markedly increased by the first

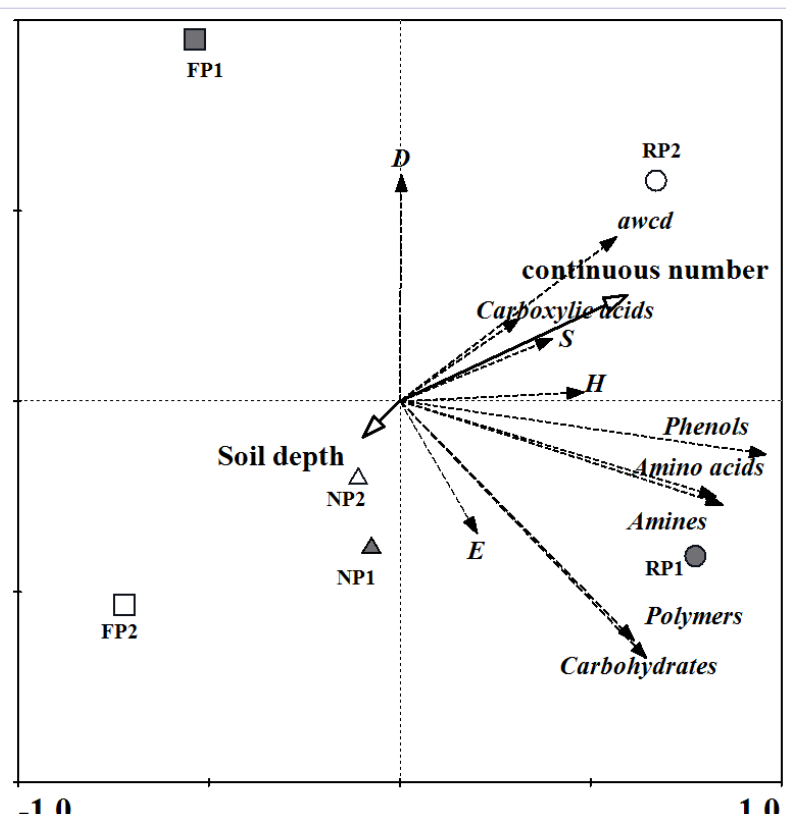

Figure 1: Redundancy Analysis (RDA) of soil microbiological properties with soil depth and the continuous number of cherry plantings. cherry planting, and decreased by replanting cherry. However, $D$ of RP2 was higher than NP2 and FP2, showing that $D$ of microbial communities could be increased by replanting cherry from the $20-40 \mathrm{~cm}$ soil layer. Shannon's diversity index $\left(H^{\prime}\right)$ of RP was obviously greater than NP and FP; otherwise, FP1 was lower than RP1 and NP1, indicating that the microbial communities were affected by the cherry planting. $H^{\prime}$ of samples from the $0-20 \mathrm{~cm}$ soil layer revealed that $H^{\prime}$ increased with the increasing number of cherry plantings. Overall, the diversity indices of samples from the $0-20 \mathrm{~cm}$ soil layer were obviously greater than those from the $20-40 \mathrm{~cm}$ layer.

Utilisation of the six carbon guild (polymer, carbohydrates, phenols, carboxylic acid, amino acids, amines) is listed in Table 3. The utilisation of carbon guild profiles varied among NP, FP, and RP. It was illustrated that the average optical density of the carbohydrates and amino acids was much higher than other carbon guilds. The maximum utilisation of carbohydrates, phenol, amino acids, and amines was RP, while the lowest was FP. At the 20-40 cm soil layer, the maximum utilisation of carboxylic acids was NP1, but NP2 was the lowest at the $20-40 \mathrm{~cm}$ soil layer. Overall, RP samples were capable of utilising more carbon guild than NP and FP.

The RDA ordination plot (Figure 1) displayed two axes that accounted for $70.9 \%$, and an object at the right side on a response (microbial) or an explanatory (continuous number of cherry plantings and soil depth) variable approximated the value of the object along that variable. Soil microbial diversity and metabolic activity were enhanced by replanting cherry, and $A W C D, E$, and the utilisation of phenols were positively correlated with a continuous number of cherry plantings $(r=0.7107,0.6055$ and 0.6443 , respectively; all $\quad P<0.05$ ). Additionally, microbial diversity and metabolic activity were weakened by a deep soil layer, and $H^{\prime}$ and $S$ were significantly and negatively correlated with soil depth ( $\mathrm{r}=-0.8141$ and -0.9245 , respectively; both $P<$ 0.05).

\section{DGGE profiles}

Clustering of the microbial communities revealed the existence of two groups with a similarity of $24 \%$, indicating relatively large differences among the samples. Although the similarity of replicates was not so high, the difference among samples was obvious. Two principal components (PCAs)

Table 2: Shannon's diversity index $\left(H^{\prime}\right)$, substrate evenness (E), substrate richness $(S)$, and Simpson dominance $(D)$ for the microbial communities in six soil samples at $96 \mathrm{~h}$.

\begin{tabular}{|c|c|c|c|c|c|}
\hline Treatment & $A W C D$ & $\boldsymbol{H}^{\prime}$ & $\boldsymbol{E}$ & $S$ & $D$ \\
\hline NP1 & $0.384 \pm 0.004^{\mathrm{bc}}$ & $3.010 \pm 0.0336^{\mathrm{ab}}$ & $1.049 \pm 0.016^{\mathrm{a}}$ & $17.667 \pm 0.667^{b}$ & $0.943 \pm 0.002^{\mathrm{ab}}$ \\
\hline FP1 & $0.4567 \pm 0.034^{\mathrm{a}}$ & $3.004 \pm 0.029^{b}$ & $1.028 \pm 0.024^{\mathrm{a}}$ & $18.667 \pm 0.882^{\mathrm{ab}}$ & $0.945 \pm 0.001^{\mathrm{a}}$ \\
\hline RP1 & $0.490 \pm 0.01 V 2^{\mathrm{a}}$ & $3.217 \pm 0.182^{\mathrm{a}}$ & $1.067 \pm 0.045^{\mathrm{a}}$ & $20.333 \pm 0.882^{\mathrm{a}}$ & $0.931 \pm 0.014^{\mathrm{ab}}$ \\
\hline NP2 & $0.346 \pm 0.012^{\mathrm{c}}$ & $2.699 \pm 0.014^{c}$ & $1.014 \pm 0.004^{\mathrm{a}}$ & $14.333 \pm 0.333^{c}$ & $0.923 \pm 0.001^{\mathrm{b}}$ \\
\hline FP2 & $0.348 \pm 0.021^{c}$ & $2.832 \pm 0.0753^{b c}$ & $1.084 \pm 0.10^{\mathrm{a}}$ & $13.667 \pm 0.667^{c}$ & $0.927 \pm 0.006^{\mathrm{b}}$ \\
\hline RP2 & $0.428 \pm 0.026^{\mathrm{ab}}$ & $2.912 \pm 0.0123^{\mathrm{bc}}$ & $1.067 \pm 0.01^{\mathrm{a}}$ & $15.333 \pm 0.577^{c}$ & $0.937 \pm 0.001^{\mathrm{ab}}$ \\
\hline
\end{tabular}

AWCD, average well colour development; NP, never-cherry-planted plot; FP, first planted cherry plot; RP, cherry replanted plot. Mean values (n = 3) with the Duncan test $(P \leq 0.05)$. 
Table 3: Average optical density of six types of six soil sample substrates at $96 \mathrm{~h}$.

\begin{tabular}{|c|c|c|c|c|c|c|}
\hline Treatment & Polymers & Carbohydrates & Phenols & $\begin{array}{c}\text { Carboxylic } \\
\text { acids }\end{array}$ & Amino acids & Amines \\
\hline NP1 & $1.745 \pm 0.144^{\mathrm{a}}$ & $4.768 \pm 0.181^{\mathrm{b}}$ & $0.806 \pm 0.096^{\mathrm{bc}}$ & $1.259 \pm 0.071^{\mathrm{a}}$ & $2.765 \pm 0.071^{\mathrm{c}}$ & $1.016 \pm 0.039^{\mathrm{ab}}$ \\
\hline FP1 & $1.117 \pm 0.085^{\mathrm{d}}$ & $2.455 \pm 0.070^{\mathrm{d}}$ & $0.449 \pm 0.047^{\mathrm{c}}$ & $0.895 \pm 0.050^{\mathrm{b}}$ & $1.795 \pm 0.037^{\mathrm{d}}$ & $0.614 \pm 0.037^{\mathrm{b}}$ \\
\hline RP1 & $1.686 \pm 0.071^{\mathrm{ab}}$ & $6.078 \pm 0.135^{\mathrm{a}}$ & $1.191 \pm 0.028^{\mathrm{a}}$ & $0.846 \pm 0.134^{\mathrm{b}}$ & $3.496 \pm 0.049^{\mathrm{ab}}$ & $1.217 \pm 0.057^{\mathrm{a}}$ \\
\hline NP2 & $1.398 \pm 0.081^{\mathrm{bcd}}$ & $3.577 \pm 0.181^{\mathrm{c}}$ & $0.588 \pm 0.049^{\mathrm{c}}$ & $0.651 \pm 0.068^{\mathrm{b}}$ & $3.154 \pm 0.053^{\mathrm{bc}}$ & $1.039 \pm 0.039^{\mathrm{ab}}$ \\
\hline FP2 & $1.338 \pm 0.048^{\mathrm{cd}}$ & $4.433 \pm 0.459^{\mathrm{b}}$ & $0.526 \pm 0.245^{\mathrm{c}}$ & $0.861 \pm 0.086^{\mathrm{b}}$ & $2.702 \pm 0.220^{\mathrm{c}}$ & $0.929 \pm 0.136^{\mathrm{ab}}$ \\
\hline RP2 & $1.465 \pm 0.096^{\text {abc }}$ & $4.423 \pm 0.007^{\mathrm{b}}$ & $1.100 \pm 0.054^{\mathrm{ab}}$ & $1.270 \pm 0.167^{\mathrm{a}}$ & $3.958 \pm 0.343^{\mathrm{a}}$ & $1.371 \pm 0.291^{\mathrm{a}}$ \\
\hline
\end{tabular}

accounted for $59.7 \%$ of the total variation and showed that each soil sample formed its own cluster. In general, the soil sample (soil layer $0-20 \mathrm{~cm}$ ) clusters exhibited a negative PCA2. On the other hand, NP clusters had a positive correlation with PCA1, while FPs were negative with both PCA1 and PCA2 (Figure 2a).

The relationship of DGGE patterns to fungal communities is shown in Figure 2b. DGGE patterns representing the fungal communities in the soil samples showed low similarity indices of $19 \%$, indicating that the treatments NP, FP, and RP were separated according to the cherry planting times. Furthermore, PCA analysis showed three relatively distinct groupings, with clusters of interstitial communities from FP to the group on the left side, the RP on the upper right side, and the NP below. Otherwise, two PCAs accounted for $56.1 \%$ of the variation. In the DGGE (Table 4, S1; Figure 3, 4), bands 2, 3, 4, 7, 8, and 9 appeared in the FP and RP. Analysis of the band sequence indicated that bands 2, 3, 4, 8 and 9 were closely related to Fusarium oxysporum f. sp, Fusarium falciforme, Fusarium oxysporum, Fusarium solani, and bands 7 was closely related Gibellulopsis nigrescens.

\section{Discussion}

Various factors, such as soil microbial communities, pests in the soil, physico-chemical soil properties, autotoxicity, and other unknown factors, might contribute to replant problems. The study on soil mineral elements and enzyme activity demonstrated that there was no significant difference in soil nutrient content and enzyme activity between RP and NP (the data is not listed). Hence, it was revealed that soil mineral elements and enzyme activity were not the key factors of cherry replant disease. To reveal the effects of replanting cherry on soil microbes, molecular microbial diversity, and the CLPP of RP were analysed. Soil microbial communities with the greatest reservoir of biological diversity were crucial for plant health [20]. Hence, the changes of microbial and metabolic structure might be the main factors resulting in cherry replant disease. It was revealed that RP has high CLPP, compared to NP and FP. Utilisation of phenols is positively correlated with the frequency of cherry plantings. It has been suggested that phenols acting as allelochemicals compounds reduce the growth of seedlings [21], and autotoxicity is an important cause of replant disease [22,23]. In many cases, allelochemicals could not only negatively affect plants, but also stimulate the growth of soilborne pathogens $[24,25]$. $\mathrm{Yu}$ et al. found that Fusarium flocciferum and Cephalosporium acremonium could alleviate the autotoxicity induced by phenolic acids in cucumber [26]. These observations suggested that there is a close relationship between utilisation of phenols and soil fungi in replanted soil. In this paper, the genomic and metabolic soil microbial communities of cherry replants were analysed, and the study on phenols content and microbial community is in progress.

DGGE analysis was adopted to detect the change of fungi and bacteria with continuous cherry plantings. In this study, significant differences in fungal communities, in relation to continuous cherry planting, were observed (Figure 2c). No obvious differences in rhizosphere bacterial community composition were observed between RP and FP (Figure 2d). Interestingly, Fusarium oxysporum, Fusarium falciforme, Fusarium solani and Verticillium nigrescens stimulated in RP. It is generally known that traditional crop rotations are an effective strategy to control many soil-borne diseases, but King et al. supposed that, due to a long period of time, pathogens such as $F$. oxysporum survived, and the effectiveness of crop rotation is weakened once a disease has occurred [27]. Accordingly, soil-borne diseases has become one of the important restricted reasons for crop yield. Numerous micro conidia produced by F. Solani on the cut surfaces of healthy wax apple trees led to diseased twigs under moist conditions, even resulting in twig blight [28]. F. oxysporum is a destructive vascular pathogen, causing vascular wilt and root diseases on a broad range of agricultural plants worldwide, leading to considerable yield and economic losses [10-12]. However, F. oxysporum have a specific relationship with plants causing wilting, for instance $F$. oxysporum formae speciales lycopersici causing with in tomato [29], F. oxysporum f.sp. cubense causing wilt in banana [30], F. oxysporum $f$. $s p$. vasinfectum causing wilt in cotton [31]. Fusarium species as pathogens could result in wilt disease in Pisum sativum and roselle plants, with damping-off and root rot wilt diseases [32,33]. Moreover, recent findings indicated F. oxysporum caused root and crown rot on sweet cherry (Prunus avium) in British Columbia. Gibellulopsis nigrescens (Synonymy: Verticillium nigrescens) as a highly controversial Verticillium spp., is pathogenic on many crops (such like potato, tomato, antirrhinum, eggplant, soybeans and M. sativa [34-38]. However, the recent report revealed that $G$. nigrescens was a promising biocontrol agent for Verticillium wilt of cotton [39].

Obviously, the results of CLPP and molecular diversity reveal that pathogens and utilisation of phenols in soil play keys roles 

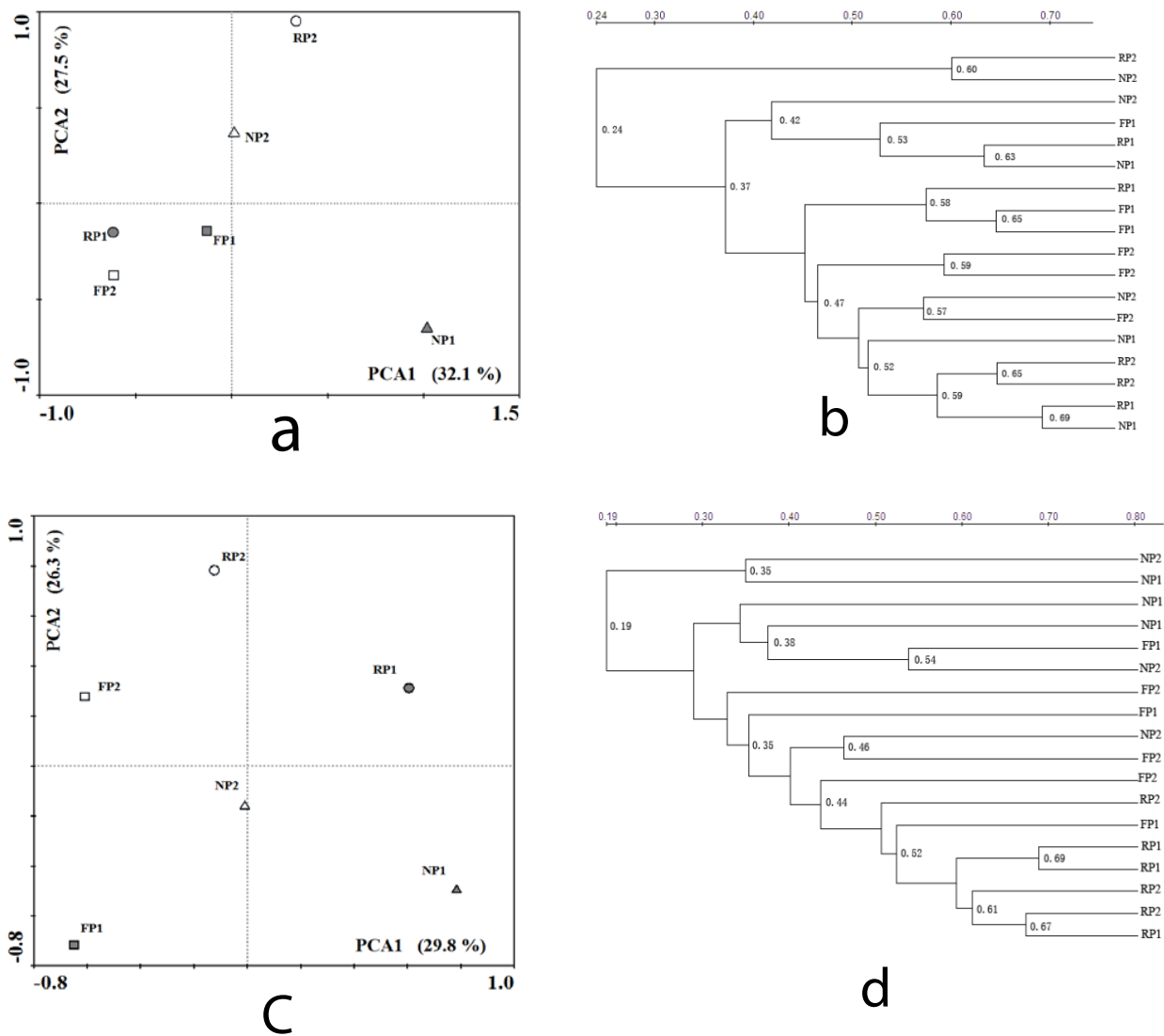

d

Figure 2: Cluster and Principal Component Analysis (PCA) of the Denaturing Gradient Gel Electrophoresis (DGGE) profiles of bacterial (a and b) and fungal (c and d) amplicons. The DGGE bands from treatments were denoted as never-cherry-planted plot (NP) 1, NP2, first planted cherry plot (FP) 1, FP2, cherry replanted plot (RP) 1, and RP2.

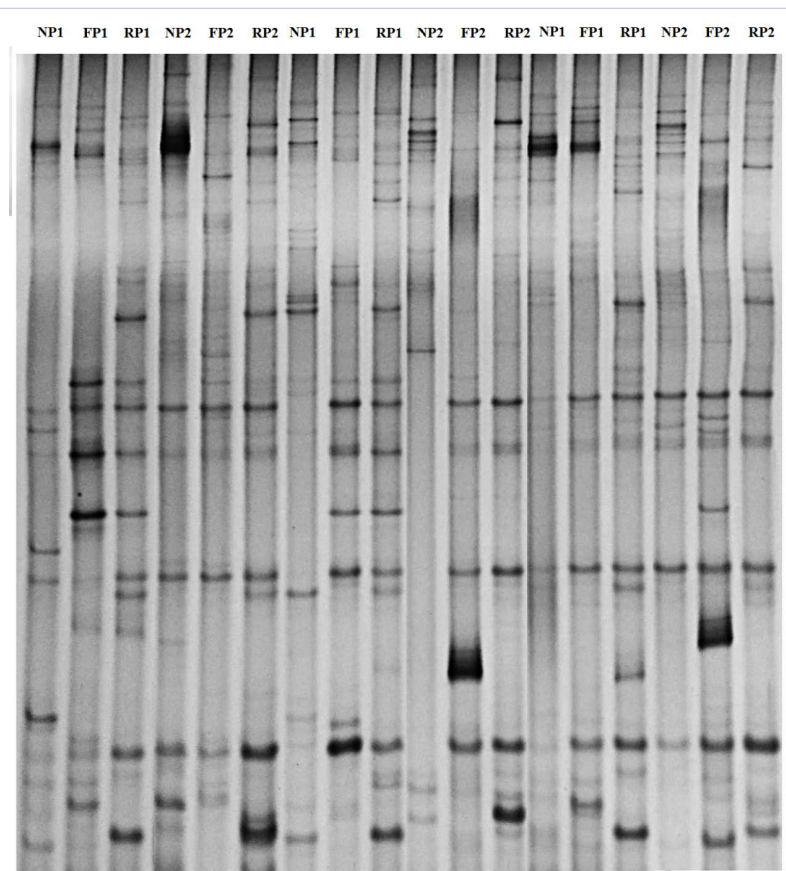

Figure 3: DGGE profile of ITS rDNA fragments of soil fungi.

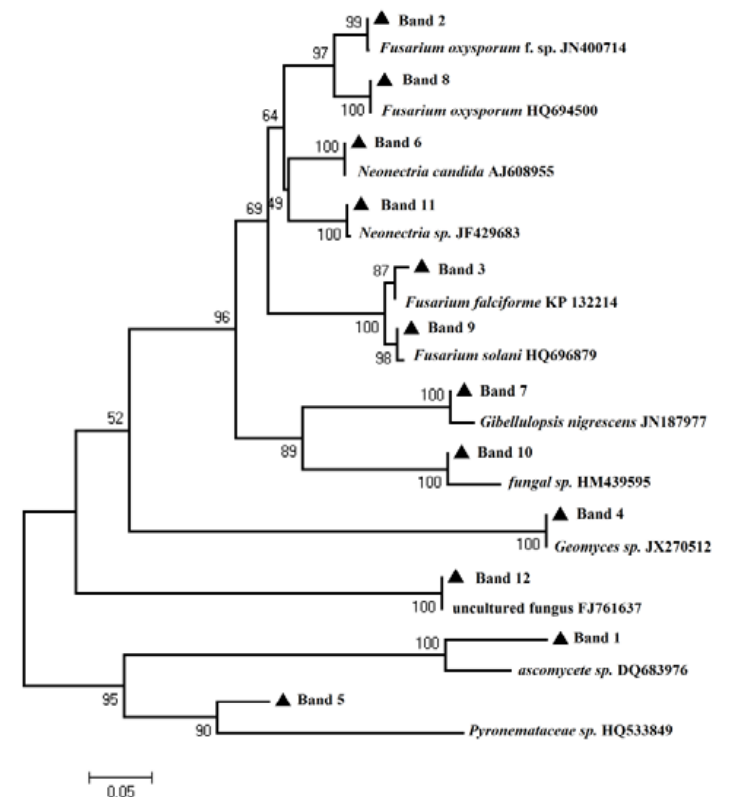

Figure 4: Neighbour-joining phylogenetic tree showing the relationship between cherry replanted soil fungi and related fungi based on the sequences of ITS regions of nuclear rDNA. 


\begin{tabular}{|c|c|}
\hline Number & Sequence \\
\hline 1 & $\begin{array}{l}\text { TTTCGCTGTGGCTGATTACGATTCGAGCTCGGTACCCGGGGATCCTCTAGAGATTGCTGCGTTCT } \\
\text { TCATCGATGCGAGAACCTAGAGATCCGTTGTTGAAAGTTTTAACTTTATTACAATAGTTATTCAG } \\
\text { ACACTACATGCAACTAAACAAGCGTTCAAACTACACCCGTGGAAGGTAACCCGCACCTGCGAACA } \\
\text { GGGCGAGCACCCGTAACTCCACGGAAGCAACAGGTACAAGTAAACAAGTGGTTGAATACAGCCA } \\
\text { CCAGCAGTCAGCGTTTTACACCTTAGCTGGAGCGTACTTTTTTAATGATCCTTCCGCAGGTTCAC } \\
\text { CTACGGAAATCGTCGACCTGCAGGCATGCAAGCTTGGCACTGGCCGTCGTTTTACAACGTCGTGA } \\
\text { CTGGGAAAACCCTGGCGTTACCCAACTTAACGCCCTTGCAGA }\end{array}$ \\
\hline 2 & $\begin{array}{l}\text { TATTCGCGTGAGTGATACGATTCGAGCTCGGTACCCGGGGATCCTCTAGAGATTTCCGTAGGTGA } \\
\text { ACCTGCGGAGGGATCATTACCGAGTTTACAACTCCCAAACCCCTGTGAACATACCTATACGTTGC } \\
\text { CTCGGCGGATCAGCCCGCGCCCCGTAAAAAGGGACGGCCCGCCCGAGGACCCCTAAACTCTGTTT } \\
\text { TTAGTGGAACTTCTGAGTAAAACAAACAAATAAATCAAAACTTTCAACAACGGATCTCTTGGTT } \\
\text { CTGGCATCGATGAAGAACGCAGCAATCGTCGACCTGCAGGCATGCAAGCTTGGCACTGGCCGTC } \\
\text { GTTTTACAACGTCGTGACTGGGAAAACCCTGGCGTTACCCAACTTAATCGCCTTGCAGA }\end{array}$ \\
\hline 3 & $\begin{array}{l}\text { ATTCGATCTGGATGATTACGATTCGAGCTCGGTACCCGGGGATCCTCTAGAGATTTCCGTAGGTG } \\
\text { AACCTGCGGAGGGATCATTACCGAGTTATACAACTCATCAACCCTGTGAACATACCTATAACGTT } \\
\text { GCCTCGGCGGGAACAGACGGCCCCGTAACACGGGCCGCCCCCGTCAGAGGACCCCCTAACTCTGT } \\
\text { TTCTATAATGTTTCTTCTGAGTAAACAAGCAAATAAATTAAAACTTTCAACAACGGATCTCTTG } \\
\text { GCTCTGGCATCGATGAAGAACGCCGCAATCGTCGACCTGCAGGCATGCAAGCTTGGCACTGGCC } \\
\text { GTCGTTTTACAACGTCGTGACTGGGAAAACCCTGGCGTTACCCAACTTAACGCCCTTGCAGA }\end{array}$ \\
\hline 4 & $\begin{array}{l}\text { AACTTCGTGTTCATGTGAGCTGATACGATTCGAGCTCGGTACCCGGGGATCCTCTAGAGATTGCT } \\
\text { GCGTTCTTCATCGATGCCAGAACCAAGAGATCCGTTGTTGAAAGTTTTAACTATTATATAGTACT } \\
\text { CAGACAGTATAAACAAACAGAGTTTAGGTCCTCTGGCAAGCGCTCGCCGGCCGGAGCCAGCAGC } \\
\text { CCGAGGGCAGGCTTGCCAAAGCAACAAAGTGTAATAAACAAAGGGTGGTAGGTTACCCGGGAGG } \\
\text { CCTTGCGGCAACCCGGGCGACTACTGTAATGATCCTTCCGCAGGTTCACCTACGGAAACCTTGTT } \\
\text { ACGACTGTTACTTCCTCTAAATGACCAAGAATCGTCGACCTGCAGGCATGCAAGCTTGGCACTGG } \\
\text { CCGTCGTTTTACAACGTCGTGACTGGGAAAACCCTGGCGTTACCCAACTTAATCGCCCTTGCAGA }\end{array}$ \\
\hline 5 & $\begin{array}{l}\text { GTAGCATTGCACATGATTACGAATTCGAGCTCGGTACCCGGGGATCCTCTAGAGATTGCTGCGTT } \\
\text { CTTCATCGATGCGAGAACCAAGAGATCCGTTGTTGAAAGTTTTAAAGTTTATGTATAAACAATAT } \\
\text { TCAGACAAAATTCAAAAAAAACAGAGTTTATAATTACCCCCCGTGCCCCCGCCCCGCCCGGGGCG } \\
\text { CGCCCCGGGCGTTACTTCCTCTAAATGACCAAGAATCGTCGACCTGCAGGCATGCAAGCTTGGCA } \\
\text { CTGGCCGTCGTTTTACAACGTCGTGACTGGGAAAACCCTGGCGTTACCCAACTTATCGCCTTGCA GA }\end{array}$ \\
\hline 6 & $\begin{array}{l}\text { AAAAGCGTAGCTCAGGCAAACCGAATTCGAAGCTTCGGTACCCGGGGATCCTCTTAGAGATTCC } \\
\text { GTAGGTGAACCTGCGGAGGGATCATTACCGAGTTTACAACTCCCAAACCCCTGTGAACATACCTA } \\
\text { TCGTTGCCTCGGCGGTGCCCGCTCCGGCGGCCCGCCAGAGGACCCCCAAACTCTTGTTTTATACA } \\
\text { GTATCTTCTGAGTAACACGATTAAATAAATCAAAACTTTCAACAACGGATCTCTTGGTTCTGGCA } \\
\text { TCGATGAAGAACGCAGCAATCGTCGACCTGCAGGCATGCAAGCTTGGCACTGGCCGTCGTTTTA } \\
\text { CAACGTCGTGACTGGGAAAACCCTGGCGTTACCCAACTTAACGCCCTTGCAGA }\end{array}$ \\
\hline 7 & $\begin{array}{l}\text { ATACAGCGAGAACATGATCGAATTCGAGCTCGGTACCCGGGGATCCTCTAGAGATTTCCGTAGGT } \\
\text { GAACCTGCGGAGGGATCATTACCGAGTACTATAACTCATAACCCTTTGTGAACCTTCATACCTGT } \\
\text { TGCTTCGGCGGCGCGCCTCCCGGGGCGTGCCCGCCGACATTATCAGAATCTCTGTTCGAACCCGA } \\
\text { CGATACTTCTGAGTGTTCTAAGCGAACTGTTAAAACTTTCAACAACGGATCTCTTGGTTCCAGCA } \\
\text { CGATGAAGAACGCAGCAATCGTCGACCTGCAGGCATGCAAGCTTGGCACTGGCCGTCGTTTTA } \\
\text { CAACGTCGTGACTGGGAAAACCCTGGCGTTACCCAACTTAACGCCCTTGCAGA }\end{array}$ \\
\hline 8 & $\begin{array}{l}\text { GGATCGTCAGATGATTACGATTCGAGCTCGGTACCCGGGGATCCTCTAGAGATTGCTGCGTTCTT } \\
\text { CATCGATGCCAGAACCAAGAGATCCGTTGTTGAAAGTTTTGATTTATTTATGGTTTTACTCAGAA } \\
\text { GTTACATATAGAAACAGAGTTTAGGGGTCCTCTGGCGGGCCGTCCCGTTTTACCGGGAGCGGGCT } \\
\text { GATCCGCCGAGGCAACAAGTGGTATGTTCACAGGGGTTTGGGAGTTGTAAACTCGGTAATGATC } \\
\text { CCTCCGCAGGTTCACCTACGGAAATCGTCGACCTGCAGGCATGCAAGCTTGGCACTGGCCGTCGT } \\
\text { TTTACAACGTCGTGACTGGGAAAACCCTGGCGTTACCCAACTTAATCGCCTTGCAGA }\end{array}$ \\
\hline 9 & $\begin{array}{l}\text { CACAAACGTAGAACTGGAAACCGAATTCGAGCTTCGGTACCCGGGGATCCTCTAGAGATTGCTGC } \\
\text { GTTCTTCATCGATGCCAGAGCCAAGAGATCCGTTGTTGAAAGTTTTAATTTATTTGCTTGTTTAC } \\
\text { TCAGAAAAACATTATAAAAACAGAGTTAGGGGTCCTCTGGCGGGGGCGGCCCGTTGTTACAGGG } \\
\text { CCGTCTGTTCCCGCCGAAGCAACGTTTTAGGTATGTTCACAGGGTTGATGAGTTGTATAACTCGG } \\
\text { TAATGATCCCTCCGCAGGTTCACCTACGGAAATCGTCGACCTGCAGGCATGCAAGCTTGGCACTG } \\
\text { GCCGTCGTTTTACAACGTCGTGACTGGGAAAACCCTGGCGTTACCCAACTTAACCGCCCTTGCAG A }\end{array}$ \\
\hline 10 & $\begin{array}{l}\text { AAAGGCGTAGACCCAGCTAAGAATTCGAGCTTCGGTACCCGGGGATCCTCTAGAGATTCTTGGTC } \\
\text { ATTTAGAGGAAGTAACAGTCGTAACAAGGTCTCCGTTGGTGAACCAGCGGAGGGATCATTACAG } \\
\text { AGTTGTAAAACTCCCAAACCTATGTGAACATACCTGTTGCCTCGGCGGCCTACCCGGCAGCTACC } \\
\text { CTGTAGCTACCCTGTAGTCCGCCGGCGGAATACAAAACTCTTGTTTTCAGTTGTCATCTCTGAGA } \\
\text { ATAAAACAAATAAATCAAAACTTTCAACAACGGATCTCTTGGTTCTGGCATCGATGAAGAACGC }\end{array}$ \\
\hline 11 & $\begin{array}{l}\text { TAAGGCGCAGACCCATGCTACCGAATTCGAGCTTCGGTACCCGGGGATCCTCTAGAGATTGCTGC } \\
\text { GTTCTTCATCGATGCCAGAACCAAGAGATCCGTTGTTGAAAGTTTTGATTTATTTAATCGGTTTA } \\
\text { CTCAGAAGACTTCTTAAATGTAATCAGGGTTTGGGGTCCTCTGGCGGGCTGTCGGAACAGGCAC } \\
\text { CGCCGAGGCAACAAATAGGTATGTTCACAGGGGTTTGGGAGTTGTAAACTCGGTAATGATCCCTC } \\
\text { CGCAGGTTCACCTACGGAAATCGTCGACCTGCAGGCATGCAAGCTTGGCACTGGCCGTCGTTTTA } \\
\text { CAACGTCGTGACTGGGAAAACCCTGGCGTTACCCAACTTATCGCCCTTGCAGA }\end{array}$ \\
\hline 12 & $\begin{array}{l}\text { ATTAACGATAGACCATGATAAGAATTCGAGCTCGGTACCCGGGGATCCTCTAGAGATTGCTGCGT } \\
\text { TCTTCATCGATGCGAGAACCAAGAGATCCGTTGTTGAAAGTTGTAATTATTAATTTGTTACTGAC } \\
\text { GCTGATTGCAATTACAAAAGGTTTATGTTTGTCCTAGTGGTGGGCGAACCCACCAAGGAAACAA } \\
\text { GAAGTACGCAAAAGACAAGGGTGAATAATTCAGCAAGGCTGTAACCCCGAGAGGTTCCAGCCCG } \\
\text { CCTTCATATTTGTGTAATGATCCCTCCGCAGGTTCACCTACGGAAATCGTCGACCTGCAGGCATG }\end{array}$ \\
\hline
\end{tabular}


Table 4: Sequences and sources used to construct phylogenetic trees.

\begin{tabular}{|c|c|}
\hline Taxon & GenBank accession No. \\
\hline Ascomycete sp. & DQ683976 \\
\hline Fusarium oxysporum f. sp. & JN400714 \\
\hline Fusarium falciforme & KP132214 \\
\hline Geomyces sp. & JX270512 \\
\hline Pyronemataceae $s p$. & HQ533849 \\
\hline Neonectria candida & HJ608955 \\
\hline Gibellulopsis nigrescens & JN187977 \\
\hline Fusarium oxysporum & HQ694500 \\
\hline Fusarium solani & HQ696879 \\
\hline fungal sp. & HM439595 \\
\hline Neonectria sp. & JF429683 \\
\hline uncultured fungus & FJ761637 \\
\hline
\end{tabular}

in cherry replant systems. It was indicated that pphenols in the soil content is closely associated with stimulated microbes in the RP. Therefore, in order to verify the relationship between them, further research is in progre.

\section{Acknowledgements}

Financial support was provided by "the Agricultural Science and Technology Innovation Program (ASTIP) of the Chinese Academy of Agricultural Sciences (CAAS-ASTIP-2016-ZFRI)" and "Central Public-interest Scientific Institution Basal Research Fund". We thank the Key Laboratory of Pomology, Zhengzhou Fruit Research Institute, and Chinese Academy of Agricultural Sciences for staff and materials support in conducting the experiments.

\section{References}

1. Sewell GWF. Effects of Pythium species on the growth of apple and their possible causal role in apple replant disease. Annals of applied Biology. 1981;97(1):31-42.

2. Catská V. Fruit tree replant problem and microbial antagonism in soil International Society for Horticultural Science. 1993;324:23-34.

3. Mazzola M. Elucidation of the microbial complex having a causal role in the development of apple replant disease in Washington. Phytopathology. 1998;88(9):930-8.

4. Utkhede RS, Smith EM. Biotic and abiotic causes of replant problems of fruit trees. In III International Symposium on Replant Problems. 1993;363:25-32.

5. Yao S, Merwin IA, Abawi GS, Thies JE. Soil fumigation and compost amendment alter soil microbial community composition but do not improve tree growth or yield in an apple replant site. Soil Biology and Biochemistry. 2006;38(3):587-599.

6. Yang JI, Ruegger PM, McKenry MV, Becker JO, Borneman J. Correlations between root-associated microorganisms and peach replant disease symptoms in a California soil. PLoS One. 2012;7(10):e46420.

7. Zhao X, Zhen W, Qi Y, Liu YJ, Yin BZ. Coordinated effects of root autotoxic substances and Fusarium oxysporum Schl. f. sp. fragariae on the growth and replant disease of strawberry. Frontiers of Agriculture in China. 2009;3(1):34-39.
8. Lagopodi AL, Ram AF, Lamers G E, Punt PJ, Van den Honde CA, Lugtenberg BJ, et al. Novel aspects of tomato root colonization and infection by Fusarium oxysporum f. sp. radicis-lycopersici revealed by confocal laser scanning microscopic analysis using the green fluorescent protein as a marker. Mol Plant Microbe Interact. 2002;15(2):172-9.

9. Dong L, Xu J, Feng G, Li X, Chen S. Soil bacterial and fungal community dynamics in relation to Panax notoginseng death rate in a continuous cropping system. Sci Rep. 2016;6:31802.

10. Beckman CH. The nature of wilt diseases of plants. St Paul: APS press, 1987.

11.Zhao QY, Dong CX, Yang XM, Mei XL, Ran W, Shen QR, et al. Biocontrol of Fusarium wilt disease for Cucumis melo melon using bio-organic fertilizer. Applied Soil Ecology. 2011;47(1):67-75.

12. Qiu MH, Zhang RF, Xue C, Zhang SS, Li SQ, Zhang N, et al. Application of bio-organic fertilizer can control Fusarium wilt of cucumber plants by regulating microbial community of rhizosphere soil. Biology and Fertility of Soils. 2012;48(7):807-816.

13. Hoestra H. Thielaviopsis basicola, a factor in the cherry replant problem in the Netherlands. Netherlands Journal of Plant Pathology. 1965;71(6):180-182.

14. Dickerson TL, Williams HN. Functional diversity of bacterioplankton in three North Florida freshwater lakes over an annual cycle. Microb Ecol. 2014;67(1):34-44.

15. Di Giovanni GD, Watrud LS, Seidler RJ, Widmer F. Fingerprinting of mixed bacterial strains and BIOLOG gram-negative (GN) substrate communities by enterobacterial repetitive intergenic consensus sequence-PCR (ERIC-PCR). Curr Microbiol. 1999;38(4):217-23.

16. Montes-Borrego M, Navas-Cortés JA, Landa BB. Linking microbial functional diversity of olive rhizosphere soil to management systems in commercial orchards in southern Spain. Agriculture, ecosystems \& environment. 2013;181:169-178.

17. Tiquia SM. Metabolic diversity of the heterotrophic microorganisms and potential link to pollution of the Rouge River. Environmental Pollution. 2010;158(5):1435-1443.

18.Zak JC, Willig MR, Moorhead DL, Wildman HG. Functional diversity of microbial communities: a quantitative approach. Soil Biology and Biochemistry. 1994;26(9):1101-1108.

19. Heuer H, Krsek M, Baker P, Smalla K, Wellington EM. Analysis of actinomycete communities by specific amplification of genes encoding 16S rRNA and gel-electrophoretic separation in denaturing gradients. Applied and environmental microbiology. 1997;63(8):3233-3241.

20. Berendsen RL, Pieterse CM, Bakker PA. The rhizosphere microbiome and plant health. Trends Plant Sci. 2012;17(8):478-86.

21. He CN, Gao WW, Yang JX, Bi W, Zhang XS, Zhao YJ. Identification of autotoxic compounds from fibrous roots of Panax quinquefolium $\mathrm{L}$. Plant and soil. 2009;318(1-2):63-72.

22.Zhao YJ, Wang YP, Shao D, Yang JS, Liu D. Auto toxicity of Panax quinquefolium L. Allelopathy Journal. 2005;15(1):67-74.

23.Zhao YJ, Wang YP, Yang JS, Liu D. A study on the rotation of crops among Panax quinquefolium, Perilla frutescens and Coix lacryma. China journal of Chinese materia medica. 2005;30(1):12-15.

24. Nicol RW, Yousef L, Traquair JA, Bernards MA. Ginsenosides stimulate the growth of soilborne pathogens of American ginseng. Phytochemistry. 2003;64(1):257-264. 
25. Zhang SS, Jin YL, Zhu WJ, Tang J,J Hu SJ, Zhou TS, et al. Baicalin released from Scutellaria baicalensis induces autotoxicity and promotes soilborn pathogens J Chem Ecol. 2010;36(3):329-38.

26. Yu JQ, Shou SY, Qian YR, Zhu ZJ, Hu WH. Autotoxic potential of cucurbit crops. Plant and Soil. 2000;223(1):149-153.

27. King SR, Davis AR, Liu W, Levi A. Grafting for disease resistance. HortScience. 2008;43(6):1673-1676

28. Wang H, Chen YS, Lin MJ, Tsou YJ, Ko WH. Severe decline of wax apple trees caused by Fusarium solani in northern Taiwan. Bot Stud. 2010;51:75-80.

29. Lievens B, Houterman PM, Rep M. Effector gene screening allows unambiguous identification of Fusarium oxysporum f. sp. lycopersici races and discrimination from other formae speciales. FEMS Microbiol Lett. 2009;300(2):201-15.

30. Ploetz RC. Fusarium wilt of banana is caused by several pathogens referred to as Fusarium oxysporum f. sp. cubense. Phytopathology. 2006;96(6):653-6.

31. Dowd C, Wilson IW, McFadden H. Gene expression profile changes in cotton root and hypocotyl tissues in response to infection with Fusarium oxysporum f. sp. vasinfectum. Mol Plant Microbe Interact. 2004;17(6):654-67.
32. Hassan N, Shimizu M, Hyakumachi M. Occurrence of root rot and vascular wilt diseases in roselle (Hibiscus sabdariffa L.) in upper Egypt. Mycobiology. 2014;42(1):66-72.

33. Rao JK. Studies on survey of Fusarium wilt of pea in Eastern Uttar Pradesh. Int. J. of Life Sciences. 2014;2(4):359-362.

34. Isaac I. A comparative study of pathogenic isolates of Verticillium. Transactions of the British mycological society. 1949;32(2):137IN4157IN5.

35. Isaac I. Some soil factors affecting Verticillium wilt of Antirrhinum. Annals of Applied Biology. 1956;44(1):105-112.

36. Isaac I. Speciation in Verticillium. Annual Review of Phytopathology. 1967;5(1):201-222.

37.Vesper SJ, Turner JT, Phillips DV. Incidence of Verticillium nigrescens in soybeans. Phytopathology. 1983;73(9): 1338-1340.

38. Hu XP, Wang MX, Hu DF, Yang JR. First report of wilt on alfalfa in China caused by Verticillium nigrescens. Plant Disease. 2011;95(12):15911591.1.

39.Zhu HQ, Feng ZL, Li ZF, Shi YQ, Zhao LH, Yang JR. Characterization of two fungal isolates from cotton and evaluation of their potential for biocontrol of Verticillium wilt of cotton. Journal of Phytopathology. 2013;161(2):70-77. 